\title{
Healthcare in need of innovation: exponential technology and biomedical entrepreneurship as solution providers (Keynote Paper)
}

\section{Michael Friebe}

Michael H. Friebe, "Healthcare in need of innovation: exponential technology and biomedical entrepreneurship as solution providers (Keynote Paper)," Proc. SPIE 11315, Medical Imaging 2020: Image-Guided Procedures, Robotic Interventions, and Modeling, 113150T (16 March 2020); doi: $10.1117 / 12.2556776$

SPIE. Event: SPIE Medical Imaging, 2020, Houston, Texas, United States 


\title{
Healthcare in need of innovation: (exponential) technology and biomedical entrepreneurship as solution providers
}

\author{
Michael H. Friebe *a, b \\ a IDTM GmbH, 45657 Recklinghausen, Germany; bHealthTec Innovation, Faculty of Medicine, \\ Otto-von-Guericke-University, 39106 Magdeburg, Germany
}

\begin{abstract}
There are significant challenges in global healthcare delivery at the moment. Some countries have abundant services, but are stuck with a rather nimble and expensive system that focuses on incremental innovations. Other geographies are still in need of basic tools, infrastructure and require completely different, inexpensive, and with that more disruptive solutions to satisfy their healthcare needs.

Next Generation Healthcare systems with a focus on prevention / early detection and pro-active therapy will employ exponential technologies (AI, Big Data, Blockchain, Sensor Technology, Synthetic Biology, Tissue Engineering, Robotics, 3D Printing, ...) that will surely lead to significant changes in the way we experience, think about, and deliver healthcare and in which a digitally empowered patient will play a more important role.

In the coming years/decades we will experience a shift from the current SICK-CARE provision to real HEALTHCARE to a focus on personal HEALTH, supported by an integration of patient generated health data with other external diagnostic and therapeutic data components creating a digital health twin as a base for prevention and patient centered precision medicine.

Education and training of Biomedical Engineers needs to be adjusted to these developments focussing on solving unmet clinical needs, which requires a solid understanding of current health problems (regional, global), future technologies, economic realities and global health markets.

The paper will present and discuss some of these future global innovation needs and the subsequent need for a change in the biomedical engineering curriculum that needs to include learning- (creativity, critical thinking, collaboration) and life skills (flexibility, leadership, social), as well as basic economic and entrepreneurial training - all of which are currently not taught or emphasized.
\end{abstract}

Keywords: Healthcare Innovation, Biodesign, Exponential Technologies, Prevention, Healthcare 4.0, Biomedical Entrepreneurship, Healthcare Ethics, Biomedicalengineering Education, Healthtec Innovation Management

1.

INTRODUCTION

If you are actively involved in Healthcare delivery or in developing innovations in and for that segment you continuously hear about the upcoming and necessary changes that will come in the next years. Phrases like "disruption is needed", "healthcare is sickcare", "rude staff and high cost", "empathy is missing in healthcare", "uneven availability" and many more are frequently used to describe the current system of providing health treatments. And most of the ones listed are correctly describing the situation in the developed world.

Different problems exists in the less developed world however, where proper healthcare services are often not available, unaffordable for a large part of the population, and where diagnostic and treatment quality is not up to the standards that we are used to living in the richer countries.

We are in the fourth industrial revolution with the evolution and application of artificial intelligence / machine learning / big data in virtually every segment, widespread use of robotics, additive manufacturing and many more dubbed as Exponential Technologies, because of their digital - exponential - base and other attributes that can lead to more democratic access for anyone. Healthcare has been very rigid in adopting these technologies and is still using the fax machine and handwritten reports as the standard of communication in many places.

*friebe@me.com; phone+49-2361-84557; friebelab.com

Medical Imaging 2020: Image-Guided Procedures, Robotic Interventions, and Modeling, edited by Baowei Fei, Cristian A. Linte, Proc. of SPIE Vol. 11315, 113150T - (c) 2020 SPIE

CCC code: $1605-7422 / 20 / \$ 21 \cdot$ doi: $10.1117 / 12.2556776$ 
One reason for that has been the application of scientific methods for healthcare decision making - evidence based medicine - that requires extensive clinical trials with statistic evaluations for regulatory approval and subsequent consideration as standard of care. This is a very expensive and time consuming approach. But this gold standard is also an average approach that does not always consider the individual health issues effectively and in certain cases also leads to detrimental effects ${ }^{1-3}$.

Current healthcare delivery - through medical practices, pharmacies, medical technology industry, hospitals, insurers, and others - and their business model is dependent on a sick person being diagnosed and subsequently treated. That is the reason why many call the current system actually SICK-CARE provision. You pay for a health insurance to cover expenses when you are sick and the providers get reimbursed for treatments, but keeping you healthy is not incentivized properly. We need to move towards a real HEALTHCARE system, that keeps you healthy and in case you are actually sick diagnoses and treats you (Patient Centric Healthcare) customized and individually tailored (Precision + Personalized Medicine). Reimbursement of these HEALTH "maintenance" services should then be based on actual outcome and patient experience (Value Based Healthcare) and no longer merely on services that were rendered. See Figure 1. for some issues with a move from SICK-CARE to HEALTHCARE and on to personal HEALTH comparing future directions with the current setup ${ }^{4-7}$

\section{From SICK-CARE to HEALTHCARE to HEALTH}

\begin{tabular}{|c|c|}
\hline $\begin{array}{c}\text { CURRENT SICK- } \\
\text { CARE SETUP }\end{array}$ & $\begin{array}{c}\text { FUTURE HEALTH } \\
\text { DELIVERY }\end{array}$ \\
\hline Treating SICKNESS & $\begin{array}{c}\text { Focussing on } \\
\text { PREVENTION }\end{array}$ \\
\hline $\begin{array}{c}\text { Procedure based } \\
\text { REIMBURSEMENT (no } \\
\text { procedure, no } \\
\text { reimbursement!) }\end{array}$ & $\begin{array}{c}\text { Value (Outcome) based } \\
\text { REIMBURSEMENT }\end{array}$ \\
\hline $\begin{array}{c}\text { Evidence based } \\
\text { Medicine with a one- } \\
\text { size fits all approach }\end{array}$ & $\begin{array}{c}\text { PERSONALIZED } \\
\text { MEDICINE }\end{array}$ \\
\hline $\begin{array}{c}\text { Lots of INVASIVE } \\
\text { Therapies }\end{array}$ & $\begin{array}{c}\text { Focus on MINIMAL- } \\
\text { INVASIVE THERAPIES }\end{array}$ \\
\hline $\begin{array}{c}\text { Treatment / Healthcare } \\
\text { provision is CENTERED } \\
\text { around the PROVIDER }\end{array}$ & $\begin{array}{c}\text { PATIENT CENTRIC } \\
\text { MEDICINE }\end{array}$ \\
\hline
\end{tabular}

\section{PRECISION + PERSONALIZED MEDICINE}

Customization of healthcare with medical decisions, treatments, practices or products being tailored to the individual patient

\section{VALUE BASED HEALTHCARE}

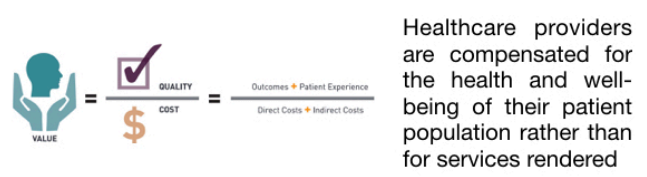

\section{PATIENT CENTRIC HEALTHCARE}

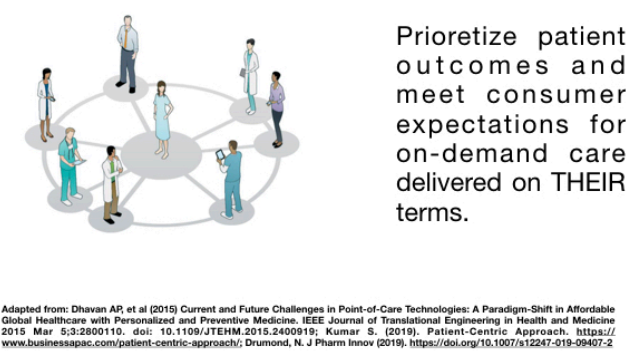

Figure 1. The table on the left shows the current setup of healthcare provision (SICK-CARE) and future developments. On the right you find some definitions of the PATIENT CENTRIC, PERSONALIZED, and VALUE BASED HEALTHCARE.

A lot of healthcare professions, regulators, payers, and politicians have opinions on how to change and what to do, but the biomedical engineer is rarely involved in the discussion. The biomedical engineer - defined for this paper as a technical domain expert working for healthcare improvements - is often considered as the one that can research and develop in an area that is considered by others as a future innovation segment. Reasons are that many engineers lack the non-technical skills needed as innovators and possibly even as entrepreneurs to determine and shape the future of HEALTHCARE and personal HEALTH. Another reason is that the current system of healthcare provision is setup in disconnected (data / communication) silos that are only reluctantly communicate with each other and share information, and that also are very rigid with respect to changing provision routes and institutional responsibilities (Outpatient / Inpatient / Regulators / Insurers / Pharmaceutical- and Medtec providers / Health Economy / Politics). 
The main intent of this paper is to highlight the need for, and subsequently present, a changed / adapted biomedical engineering curriculum that includes 21 st century learning learning-, life-, and innovation-generation- skills that would allow the biomedical engineer to play a more prominent role in healthcare innovation generation, which would be beneficial to the entire process.

\section{HEALTHCARE TECHNOLOGY STATUS + EXPONENTIAL TECHNOLOGIES}

\subsection{Health Determinants}

Personal Health is determined by a multitude of factors, most importantly by the socioeconomic circumstances (your upbringing, education, income, family status), your genetic base, your individual behavior (what you eat and drink, drug use, sexual behavior, exercise), and your physical environment (water and air pollution, crime). Only 10-15\% of your health determinants depend on the quality of the healthcare provision ${ }^{3}$ (see figure 2).

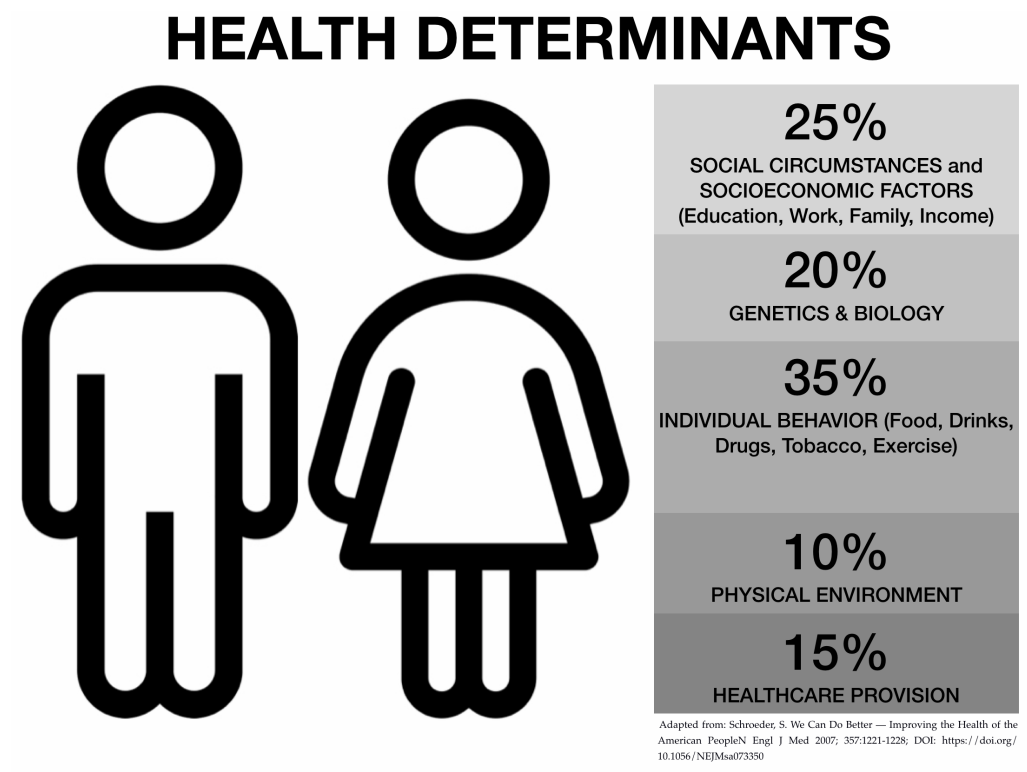

Figure 2. Importance of Health determinants - only $10-15 \%$ is actually related to the quality of Healthcare Provision.

So we spend Trillions on diagnosis, treatment, clinical staff, hospitals, pharmaceuticals, medical technology, and related research while our health would benefit more, if we adjust our individual behavior, improve socioeconomic factors for everyone, clean water/air, and learn more about genetics and their effect on the human biology. This is not included to frustrate the biomedical engineer, but rather to indicate the vast innovation potential that exists and that has as a basis the combination of many data points (genetic information + sensor input + deep learning + big data to provide early diagnosis and prevention input that can also influence individual behavior).

You can easily see the opportunities if genetics, individual behavior, and actual healthcare provision are integrated for the purpose of improving the quality of personal health, allow for very early diagnosis and with that prevent a disease from developing or reduce treatment cost dramatically. You can also realize that this could lead to a significant change in healthcare delivery and which would then be associated with new HEALTH business models.

While the challenges of providing high-quality healthcare in developing countries are different than those in developed countries, there share a common goal: to provide access to health monitoring and assessment technologies to people with limited or no healthcare facilities, or with geographically distant or difficult to physically access facilities 4 .

\subsection{Move to Prevention and Homecare}

Globally, it is obvious and desirable to move to very early diagnosis and to shift some of the diagnosis (initially for the most common sicknesses), treatment, and monitoring from expensive in- to outpatient facilities and on to the private home. A wearable, measuring temperature and other vital parameters, combined with a breath / cough analyzer 
(comparing the results to a previously acquired healthy baseline) could surely make an easy distinction between a normal flue and a more serious health issue. The data file could then be send to a physician that reviews (or not, once accepted as the gold standard), maybe consults with the patient via an Internet connection, writes and forwards a prescription / handling advise, and forwards automatically to a pharmacy that delivers the medication. That would not require a physical visit to a doctors office, subsequently keep the patient healthier, allow more time for the doctor to spend with more seriously ill patients, and obviously reduce the cost of diagnosis and treatment.

The more we invest in early prevention and the more we allow for healthcare provision to shift from acute- to mid-leveland on to homecare the more we can increase the individuals quality of live and the more we can reduce associated costs (see Figure 3) $)^{5,6}$.

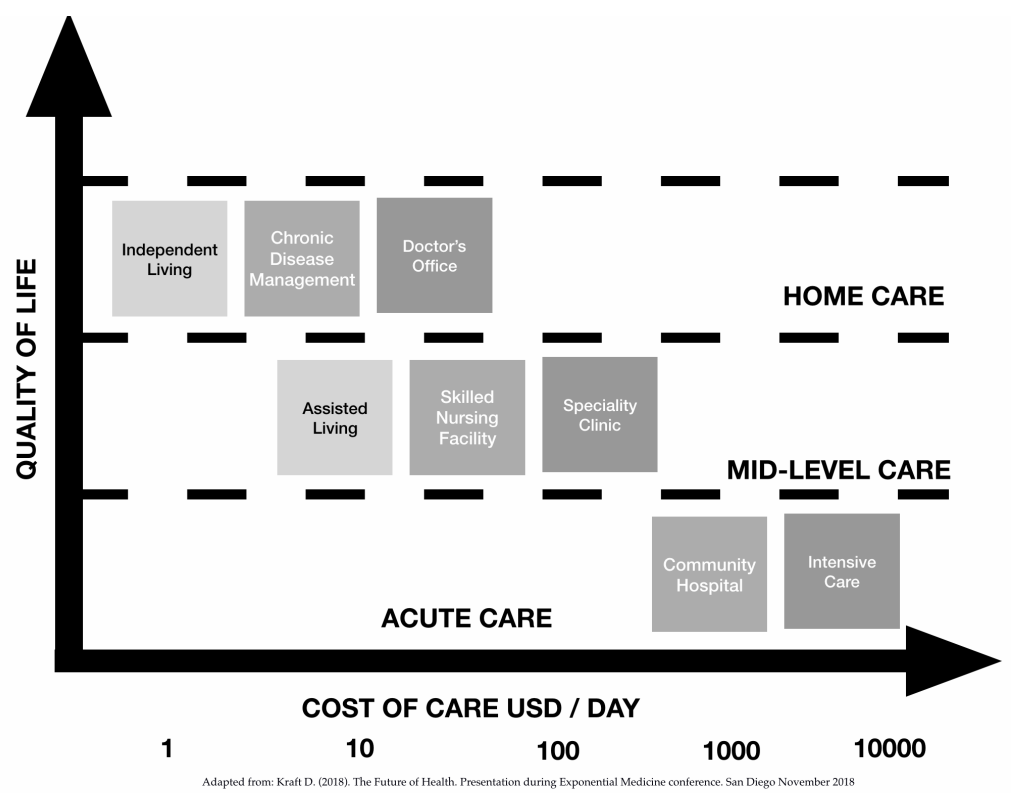

Figure 3. Quality of Care versus Health Care Cost. The more we shift from acute- and mid-level- to home-care the more we increase the individual patients quality of life and reduce healthcare delivery cost.

So there are very good arguments that we will see a paradigm shift in healthcare delivery from treating the sick to preventing from becoming sick through a a value based, patient centric, and personalized healthcare. But that requires that some of the exponential technologies that are already available will be quickly adopted for the healthcare segment. The current healthcare business models in the developed world do not necessarily allow/incentivize cheap, portable, wearable IoT (Internet of Things), and intelligent (through integrated or connected machine and deep learning algorithms) devices or systems.

Medical Technology developments are currently mainly focussed around incremental innovations of existing systems, but that will not provide a new approach to medicine. For that we need more disruptive approaches and technologies that address cost and concentrate on prevention, the closer to the patients home the better. The available sensors for vital sign monitoring and the available artificial intelligence based apps in combination with vast (not always correct) medical information available online have already created a semi-informed patient that will be significantly more empowered with additional systems, devices, and software apps that will become available in the coming years ${ }^{7-9}$.

Future Healthcare on a global level will need to

1. reduce cost,

2. increase availability,

3. focus on prevention and very early diagnosis,

4. provide improved outcomes and

5. increase the healthy life. 


\subsection{Exponential Technologies}

Working on linear (incremental) improvements of existing technologies will not provide a solution to these problems. They actually have shown to not greatly improve the quality of care, while simultaneously increase the associated cost significantly.

Disruption, replacing a current technology with something of equal or better quality, but with greatly reduced cost (demonetization) and size (dematerialization) could lead to a significantly increased global availability (democratization). An exponential technology as a base of disruption is characterized by an exponential advance / improvement in quality of care, size, speed, and manufacturing/delivery cost and has a technology or delivery method that is data based (digital).

It is sometimes difficult to recognize them as potential disruptors, as they typically go through an initial disappointment phase, where the technology is bulky, expensive and does not compare favorably with existing systems. An example is Quantum Computing that certainly has the potential to be a future technology base, but still is too complicated, too large and too expensive. But ask yourself, if you believe that it will reduce size, cost and complexity in the coming years and assuming it will, if it can provide advantages for certain unmet / unresolved clinical problems.

CRISPR gene editing technology (detect and correct genes that are known to cause diseases), surgical robotics (accurate therapy, also remotely), 3D printing (implants) and tissue engineering (skin, tissue, organs), small sensors (maybe even implantable or ingestible), machine learning combined with big data approaches evaluating all the past and present health data sources for very early diagnosis and prevention, and blockchain technology (data privacy and protection, value chain, reimbursement) are technologies that most likely qualify to meet these criteria in the near future and be able to provide solutions for the healthcare needs of the future (see Figure 4).

However, as all these are predictions for the future the effects and the new business models that will develop around the new healthcare workflows are difficult to predict.

\section{WE CAN NOT PREDICT EXPONENTIAL IMPLICATIONS}

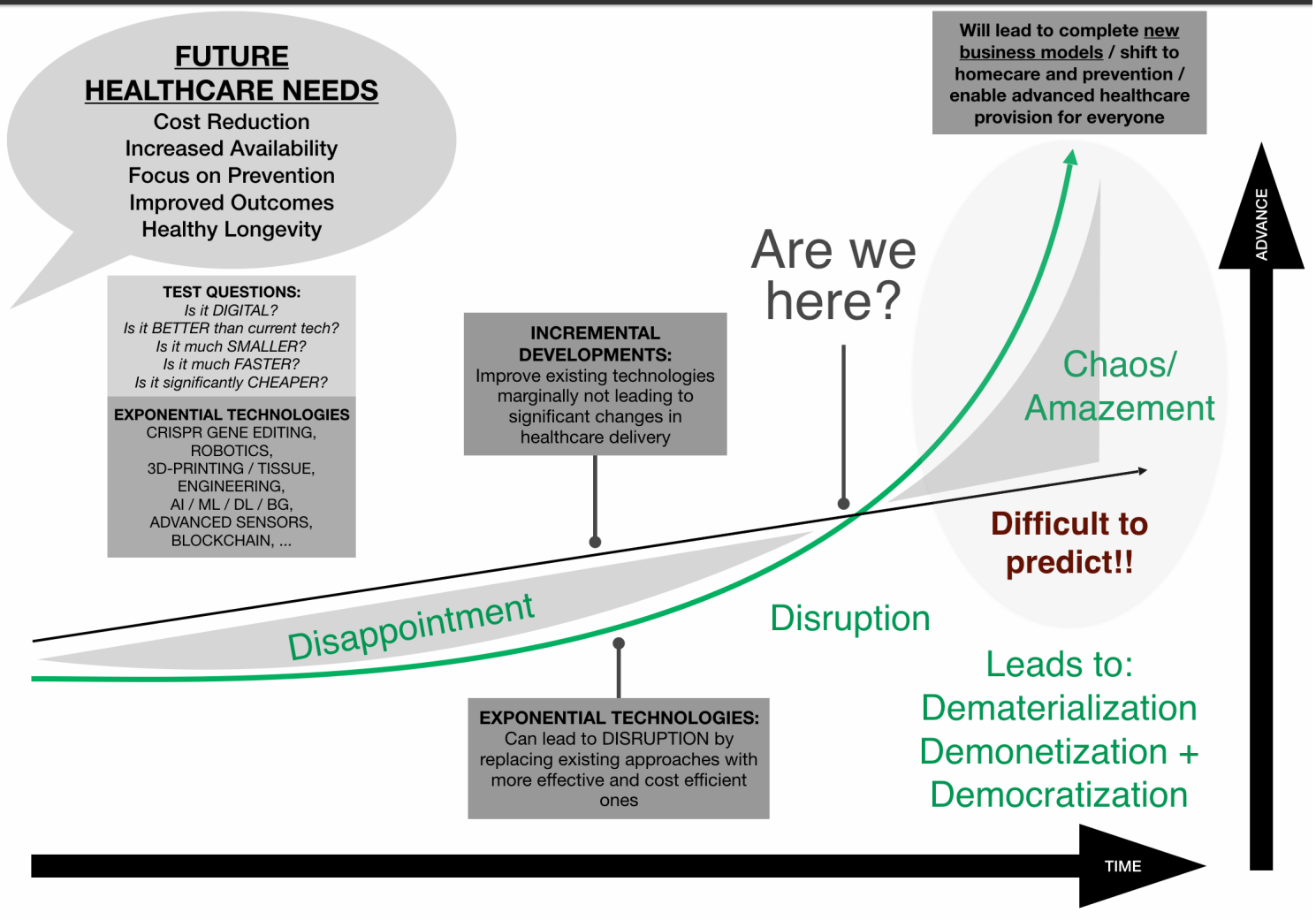

Figure 4. What describes an Exponential Technology and what does Disruption by these technologies lead to. 
It is firmly believed (and there is quite a bit of evidence for that already) that the use of technology involving artificial intelligence will help reduce waiting times, create efficiencies, and make medicine more humane, without replacing doctors ${ }^{10-14}$.

But a major weaknesses of the AI algorithms is that they are black boxes without a clear explanatory pathway on how they come up with diagnostic or treatment conclusions. It is difficult for a clinician to accept an opinion / result that is not comprehensible and that cannot be explained to the patient. Questions about safety, regulatory acceptance, equality, ethics, and data protection are additional concerns that need to be addressed ${ }^{12,14}$.

And we currently are incentivizing all providers treating diseases after they occur rather than to foster wellness, which would require the health insurance and other payers to reward keeping patients healthy, a clear organizational paradigm shift ${ }^{15}$.

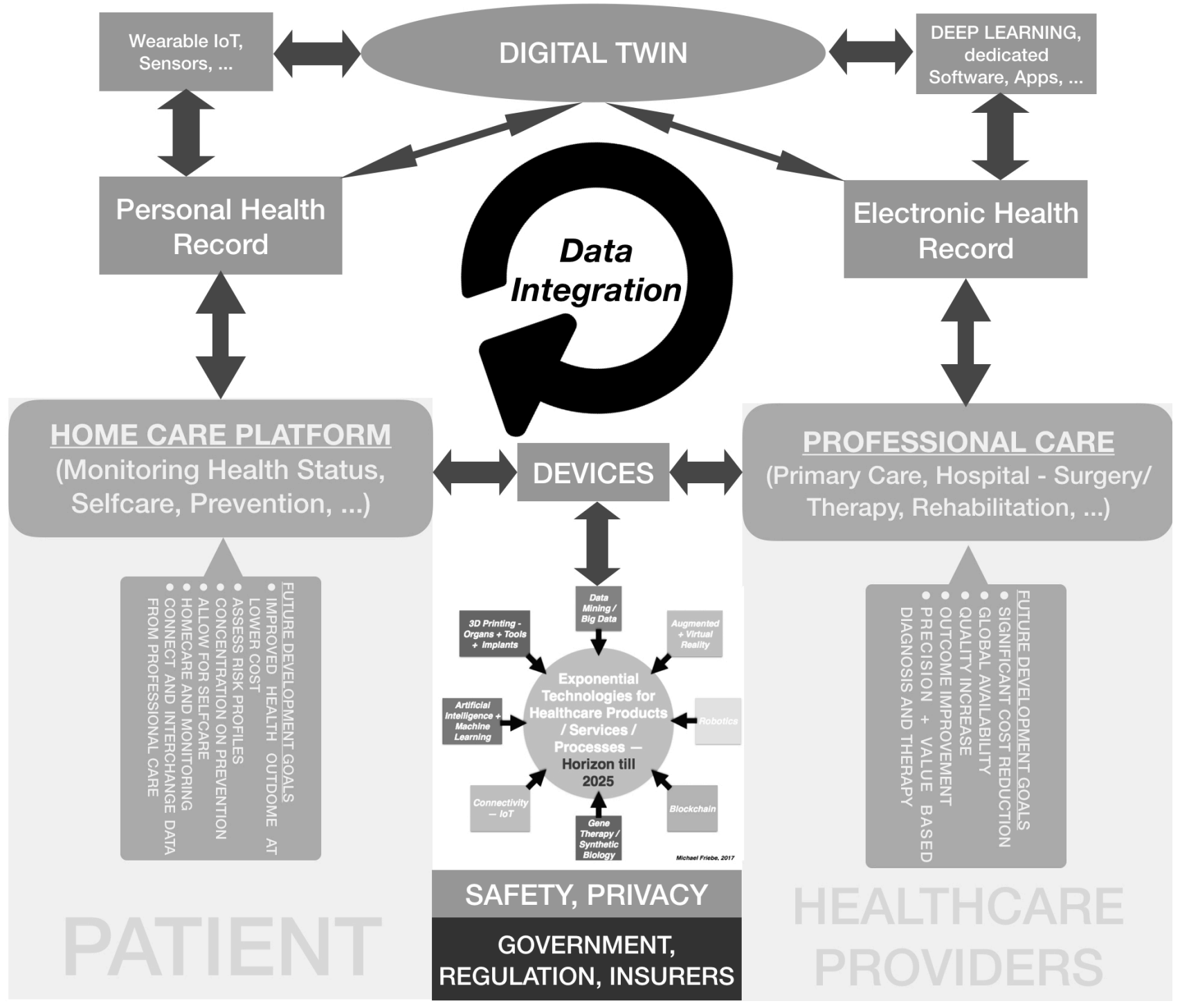

Figure 5. Data Integration of Personal Health Data and Electronic Health Record Data will create a Digital "Health" Twin that will be able to provide proactive input and will empower the patient as the owner and manager of their own health data. 
It is indisputable however that smartphones with sensors and wearable IoT will provide multi-functional medical input that will integrate - lets assume a safe and protected digital environment — through a home-care platform and with other external and forensic (genetic information, health status of ancestors, past digitized health records) information to a Personal and Private Health Record.

The health data generated in the professional care (Electronic Health Record - still to be developed in most countries) will be merged to create a Digital Twin that will eventually be able to manage the health status proactively, personalized and inform/advise about future implications and with that will increase the role of the patient managing their own health

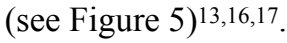

It will also allow patient self management and monitoring of chronic conditions ${ }^{14}$ and help rethink the healthcare delivery for the elderly population ${ }^{18,19}$.

\subsection{What is Needed}

The ultimate objective is the provision of better care and improved health outcomes for all people regardless of their physical, mental health, social, cultural and learning needs, and for people with low digital literacy or those less able to access technology. Personalized medicine also means personalized service covering people that may need different services and some people will never use digital services themselves directly but will benefit from others using digital services. Typically the weakest within a system are also the ones with the highest risk of being left behind. So future health delivery investments - besides continuously innovation and related research activities - will need to be in clinical infrastructures, digital services, and technology and integration adapted skills and cultures for the patients and the clinical staff.

A success measure for the success of these investments would be if (adapted quote from ${ }^{16}$ ),

- a healthy person can stay healthy and active (using wearables, diet-tracking apps) and can co-ordinate with their clinician / general practicioner about targeted preventative care

- a person with any long-term condition can find a variety of supportive apps and technologies to meet their needs, created by the market and working seamlessly with the DIGITAL TWIN / EHR data and care

- a developer or researcher can easily see everything they need to know to work with the DIGITAL TWIN / EHR system data or build something to sell to the national health provider

- a clinician or social care worker has digital tools and services that support them in doing their jobs and allow them to provide care and support for their patient with a minimum of friction and distraction

- the world-leading research using the massive body of health data producing groundbreaking new clinical treatments

- an analyst can work discover where there are gaps in the market to bring better innovations to the system

- a developer, company or researcher who has hit a barrier around access to data or users can get rapid, responsive help from the national health provider / coordinator to keep the project moving

- a developer or researcher can rapidly collect evidence on the real-world impact of their tool, using the same efficient digital methods and datasets that allowed them to develop a digital tool in the first place

- a commissioner, clinician or person using health and care services can rapidly access evidence on the impact of the digital tools being offered

4.

\section{BIOMEDICAL ENGINEERING SKILLSET}

Education and training of Biomedical Engineers need to be adjusted considering these developments and challenges. The engineer should be part of the innovation process as developer, innovator, and entrepreneur.

The Stanford „BIODESIGN process of innovation medical technologies“ and extensions of that provides a good base for a HEALTHTEC INNOVATION TRACK within a biomedical engineering curriculum or as an external certificate program for anyone dealing with future technology developments in the healthcare space $9,20,21$. 
This process focuses on solving unmet clinical needs, which requires a solid understanding of current health problems (regional, global), through observation of the clinical processes and with the knowledge of future technological developments (IDENTIFY), followed by application of innovation generation tools (INVENT), and an iterative reevaluation (going back to the stakeholders to confirm the findings and verify the ideas) within economic realities and a subsequent IMPLEMENTATION. To deliver on the potential of these technologies, collaborations between stakeholders will prove to be essential.

The World Economic Forum and the Boston Consulting group published a paper on 21st century workforce skills. Besides the literacy skills taught at university two additional skill sets were considered equally important. LIFE SKILLS that include curiosity, taking initiative, leadership, social awareness and responsibility (ethics, moral) and LEARNING SKILLS that consist of the ability to critically think, to work in collaborative and interdisciplinary teams, and to communicate ${ }^{22}$. Education technologies could help close this skills gap (see Figure 6). To the knowledge of the author no university offers this skill set as part of a biomedical engineering training at the moment.

Innovation (= Invention x Commercialization) rarely comes from within one (technology) segment, but most often happens, when several domain expertise come together. Particularly in healthcare that is likely true, where several technology areas (e.g. electronics to develop the sensors, mechanical and material engineering to develop biocompatible components, signal processing expertise to prepare the data, computer science to establish user interface and artificial intelligence) meet the clinical users that understand and describe the problems, and the patient that needs empathy and a solution. Putting all these expertise together and manage the implementation all the way to market introduction and actual patient use is what a healthcare entrepreneur would do.

The Biomedical Engineer should be able to become a HEALTHTEC INNOVATION expert through training in the needed specific domain knowledge, but also by providing courses / lectures seminars on the previously mentioned 21 st century skill set. This could be achieved by the equivalent of a mix of online and presence learning with a 15 ECTS equivalent time investment and a validated innovation team-proposal as final project. After completion of this track it should be possible to IDENTIFY unmet clinical needs, INVENT / IDEATE initial solutions for these needs, and evaluate/verify on whether one or several of these ideas can be IMPLEMENTED preferably in an interdisciplinary team of ENGINEERING expertise, MEDICAL Know-How within ECONOMIC realities - the author dumbs it the I3-EME approach 9 .

5.

\section{CONCLUSION}

Healthcare is in dire need of innovation. A biomedical engineer could be the innovation liaison and organizer between the technology development, the clinical users / needs, and the patient. Healthcare needs to move from treating sick people to preventing people from getting sick and will need to reduce the healthcare cost significantly to make it available for everyone on this planet.

Exponential technologies will likely disrupt the way we experience healthcare at the moment, eventually leading to a Digital Twin with an empowered patient in control of their own health. The role of the health care providers will also change and new business models will subsequently develop.

There will be many opportunities for domain experts that are trained on innovation generation within the healthcare domain and together with clinical users, but additional soft skill education and training is needed for a biomedical engineer to play a significant role in that.

A proposed HEALTHTEC INNOVATION TRACK of additional learnings could provide the base for that.

Final words on the healthcare innovation process:

- Work with clinicians, nurses, patients and be an empathetic observer in a clinical setup!

- Don't follow an idea from a clinical stakeholder without investing time in properly understanding the problem.

- Think global! A problem in the US may not be a problem in Egypt ... and vice versa.

- Understand regional needs and healthcare economies.

- Always innovate around a problem (need) not around a technology — attempt to quality and availability, reduce errors and cost. 


\section{Future Biomedical Engineering Education HEALTHTEC INNOVATION TRACK}

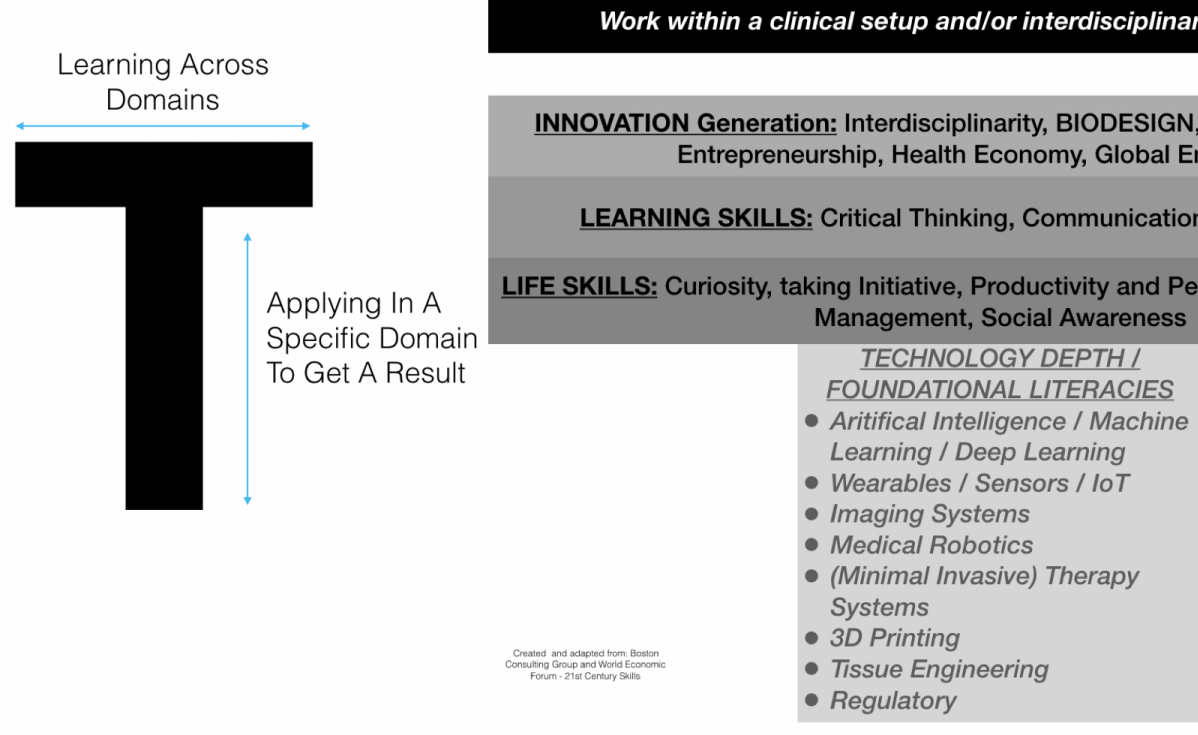

\section{Work within a clinical setup and/or interdisciplinary environment}

INNOVATION Generation: Interdisciplinarity, BIODESIGN, Unmet Clinical Needs, Entrepreneurship, Health Economy, Global Environment

LEARNING SKILLS: Critical Thinking, Communication and Collaboration

Applying In A

Specific Domain

Management, Social Awareness

FOUNDATIONAL LITERACIES

Aritifical Intelligence / Machine

Learning / Deep Learning

Wearables / Sensors / lo

- Imaging Systems

Therapy

- Tissue Engulatory

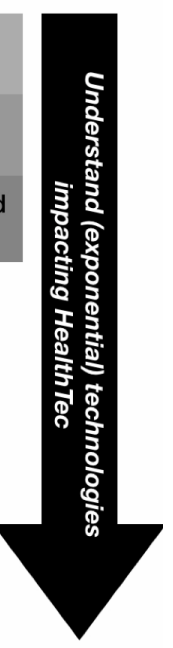

\section{I3-EME (IDENTIFY - INVENT - IMPLEMENT - ENGINEER / MEDICAL + CLINICAL KNOW-HOW / ECONOMICS)}

Figure 6. Besides the domain depth that comes with a biomedical engineering education the academic education (or subsequent training / specialization in a Healthtec Innovation Track) should include in the future innovation generation in an interdisciplinary environment, including entrepreneurship and health economy basics, as well as the 21 st century learningand life-skills.

\section{REFERENCES}

[1] Hendricks, D., "Why Entrepreneurs Are the Future of Healthcare.". http://www.inc.com/ drew-hendricks/whyentrepreneurs-are-the-future-ofhealthcare.html (2016).

[2] Christensen, C., Bohmer, R., Kenagy, J., "Will Disruptive Innovations Cure Health Care?", HARVARD BUSINESS REVIEW, Sept-Oct 2000 issue. https://hbr.org/2000/09/willdisruptiveinnovations-cure-health-care (2000).

[3] Schroeder, S., "We Can Do Better - Improving the Health of the American People", N Engl J Med 2007; 357:1221-1228 (2007).

[4] Dhavan, A., et al, "Current and Future Challenges in Point-of-Care Technologies: A Paradigm-Shift in Affordable Global Healthcare with Personalized and Preventive Medicine.", IEEE Journal of Translational Engineering in Health and Medicine 2015 Mar 5;3:2800110 (2015).

[5] Kraft, D., "The Future of Healthcare Is Arriving - 8 Exciting Areas to Watch.". https:// singularityhub.com/2016/08/22/exponential-medicine-2016-the-future-of-healthcare-iscoming-faster-than-you-think/ (2016). 
[6] Friebe, M., [International Healthcare Vision 2037. New Technologies, Educational Goals and Entrepreneurial Challenges], Otto-von-Guericke-Universität, Magdeburg, ISBN: 978-3-944722-59-7 (2017).

[7] Diamandis, P., "Disrupting todays healthcare system.”. http://www.diamandis.com/blog/ disruptingtodays-healthcare-system (2016).

[8] Mesko, B. “The Medical Futurist.”, http://www.tmf.com

[9] Friebe, M., "Exponential Technologies + Reverse Innovation = Solution for Future Healthcare Issues? What Does It Mean for University Education and Entrepreneurial Opportunities?", Open Journal of Business and Management, 5, 458-469 (2017).

[10] Joshi, I., "Waiting for deep medicine.", Lancet 2019, 393:1193-1194, https://doi.org/ 10.1016/S0140-6736(19)30579-3 (2019).

[11] Watson, D., Krutzinna, J., Bruce I. et al., "Clinical applications of machine learning algorithms: beyond the black box.”, BMJ. 2019, 3641886 (2019).

[12] Matuchansky, C., "Deep medicine, artificial intelligence, and the practising clinician.", The Lancet, VOLUME 394, ISSUE 10200, P736, AUGUST 31, 2019. DOI:https://doi.org/ 10.1016/S0140-6736(19)31235-8 (2019).

[13] Kher, RK., "Mobile and E-Healthcare: Recent Trends and Future Directions.", J Health Med Econ. 2016, 2:10 (2016).

[14] Kabir, M., "Does artificial intelligence (AI) constitute an opportunity or a threat to the future of medicine as we know it?", Future Healthcare Journal 2019, Vol 6, No 3: 190-1 (2019).

[15] Christensen, C., Waldeck, A., Fogg, R., “The Innovation Health Care Really Needs: Help People Manage Their Own Health.”, Harvard Business Review Oct. 30, 2017. https:// hbr.org/2017/10/the-innovation-health-care-really-needs-help-people-manage-their-ownhealth?autocomplete=true (2017).

[16] UK Department of Health and Social Care, "The future of healthcare: our vision for digital, data and technology in health and care", Published 17. October 2018. https://www.gov.uk/ government/publications/the-future-of-healthcare-our-vision-for-digital-data-andtechnology-in-health-and-care/the-future-of-healthcare-our-vision-for-digital-data-andtechnology-in-health-and-care (2018).

[17] Jin, J., et al., "Patient-centric authorization framework for electronic healthcare services.", Computers \& Security. https://doi.org/10.1016/j.cose.2010.09.001 (2010).

[18] Kumar, S., "Patient-Centric Approach". https://www.businessapac.com/patient-centricapproach/ (2019).

[19] Chaturvedi, N., Agarwal, A., "How European Health Care Providers Are Engaging Doctors with New Technologies.”, Harvard Business Review November 08, 2018 (2018).

[20] Zenios, S., Makower J., Yock. P. Et al. [Biodesign: The Process of Innovating Medical Technologies], Cambridge University Press, 2009

[21] Friebe, M. and Traub, J., "Image guided surgery innovation with graduate students a new lecture format.", Current Directions in Biomedical Engineering 09/2015; 1(1) (2015).

[22] Bailey, A., Kauffman, B., Subotic, S., "Education Technology and the 21st-Century Skills Gap.”. https://www.bcg.com/publications/2015/public-sector-education-technology-21stcentury-skill-gap.aspx (2015) 